\title{
"Overgrowth: Missing a Tumor" Acromegaly without Imaging Evidence of Pituitary Adenoma and No Ectopic Source: A Case Report
}

\author{
Nicodemus Ong ${ }^{1}$ and Rosa Allyn Sy² \\ ${ }^{1}$ Department of Internal Medicine, Cardinal Santos Medical Center, Philippines \\ ${ }^{2}$ Endocrine, Metabolic and Diabetes Section, Cardinal Santos Medical Center, Philippines
}

\begin{abstract}
Growth hormone - secreting pituitary adenomas are the cause of acromegaly in $95 \%$ of patients. In rare circumstances a pituitary adenoma on magnetic resonance imaging cannot be found; hence, a search for an ectopic source of $\mathrm{GH}$ production is done. Even rarer is an acromegalic patient without an ectopic source and without imaging evidence of pituitary adenoma. We report a case of acromegaly with no evidence of a pituitary adenoma and no evidence of an ectopic source after imaging studies; who underwent medical therapy with improving biochemical and clinical parameters.
\end{abstract}

Key words: acromegaly, pituitary neoplasms, adenoma, magnetic resonance imaging, sandostatin, cabergoline, case report

\section{INTRODUCTION}

Acromegaly is a rare, chronic disorder of excessive growth hormone $(\mathrm{GH})$ and consequent overproduction of insulin growth factor-1 (IGF-1) from the liver. IGF-1 in large part mediates the effects of GH. Acromegaly is characterized phenotypically by progressive acral and facial disfigurement and is associated with cardiovascular, respiratory, metabolic, and gastrointestinal complications. Growth hormone secreting pituitary adenomas are the cause of acromegaly in $95 \%$ of patients, other rare causes are ectopic GH-secreting tumor, and ectopic or hypothalamic growth hormone releasing hormonesecreting tumor. Diagnosis of acromegaly is suggested by clinical features and confirmed by an elevated age- and sex-matched serum IGF-1 level and GH levels that fail to suppress to $<1 \mathrm{ug} / \mathrm{L}$ after an oral glucose load. Confirmation of the source is done using Cranial MRI pituitary protocol. Typically, after the MRI imaging, a GH-secreting pituitary adenoma will be identified and surgical resection of the tumor performed. Surgery is the treatment of choice and frequently results in biochemical remission after complete removal of the adenoma.

In rare circumstances, a pituitary adenoma on magnetic resonance imaging cannot be found; a search for an ectopic source of GH production is done. Even rarer is an acromegalic patient without an ectopic source and without an imaging evidence of pituitary adenoma. The treatment for this subset of patients is not well defined. We present our experience in dealing with such a case.

eISSN 2308-118x

Printed in the Philippines

Copyright $(2017$ by the JAFES

Received: May 31, 2017. Accepted: August 22, 2017

https://doi.org/10.15605/jafes.032.02.13

\section{CASE}

Our patient is a 76-year-old female of Chinese descent who came in for initial consult in year 2000 at age 61 at another institution, due to symptoms of upper airway obstruction, i.e., choking, snoring and difficulty of breathing on lying supine. On examination, she was noted to have enlarged hands, feet, tongue, lip, and nose; and a prominent mandible. She is a diabetic, maintained on oral hypoglycemic medications. An initial impression of acromegaly was given. Workup revealed an elevated IGF1; and confirmed with an unsuppressed growth hormone levels on oral glucose challenge (Table 1). An MRI of the sella with contrast (pituitary protocol) revealed a normal pituitary. A CT scan of the neck, chest and abdomen done were also unremarkable.

After explaining treatment options and the risks associated with each intervention, our patient opted for medical management. Patient was started on octreotide [Sandostatin-LAR] $20 \mathrm{mg}$ monthly for 8 months, but repeat IGF-1 level was persistently elevated. Hence, cabergoline, $0.5 \mathrm{mg} / \mathrm{tab}, 2$ tablets twice a week was added

$\begin{aligned} & \text { Table 1. Laboratory workup of the patient on diagnosis } \\
& \text { (year 2000) }\end{aligned}$
\begin{tabular}{ll}
\hline GH Suppression Test & Reference range < $0-2 \mathrm{ng} / \mathrm{mL}$ or \\
(After 100g oral glucose) & undetectable \\
Baseline & $3.8 \mathrm{ng} / \mathrm{ml}$ (Reference range: $0-10)$ \\
60 minutes & $4.4 \mathrm{ng} / \mathrm{ml}$ \\
90 minutes & $8.5 \mathrm{ng} / \mathrm{ml}$ \\
& $692 \mathrm{mcg} / \mathrm{mL}$ (Reference range: $114-492)$ \\
\hline IGF-1 &
\end{tabular}

Corresponding author: Nicodemus L. Ong, MD

Department of Internal Medicine, Cardinal Santos Medical Center

10 Wilson Street, Greenhills West, San Juan, Metro Manila, Philippines, 1502

Tel. No.: +632-727-0001 loc. 3510

E-mail: nico.ongmd@yahoo.com 
ONLINE FIRST | September 6, 2017 | https://doi.org/10.15605/jafes.032.02.13

\begin{tabular}{|c|c|c|c|c|c|c|c|c|}
\hline IGF-1 (ng/ml) & $\begin{array}{l}7 / 18 / 2015 \\
52(90-220)\end{array}$ & $\begin{array}{l}\text { 4/12/2013 } \\
243(64-188)\end{array}$ & $\begin{array}{l}2 / 15 / 2011 \\
249(64-188)\end{array}$ & $\begin{array}{l}4 / 16 / 2010 \\
301(64-188)\end{array}$ & $\begin{array}{l}7 / 11 / 2006 \\
438(91-443)\end{array}$ & $\begin{array}{l}3 / 10 / 2005 \\
253(91-443)\end{array}$ & $\begin{array}{l}\mathbf{1 2 / 2 / 2 0 0 4} \\
411(91-443)\end{array}$ & $\begin{array}{l}2000 \\
692(114-492)\end{array}$ \\
\hline
\end{tabular}
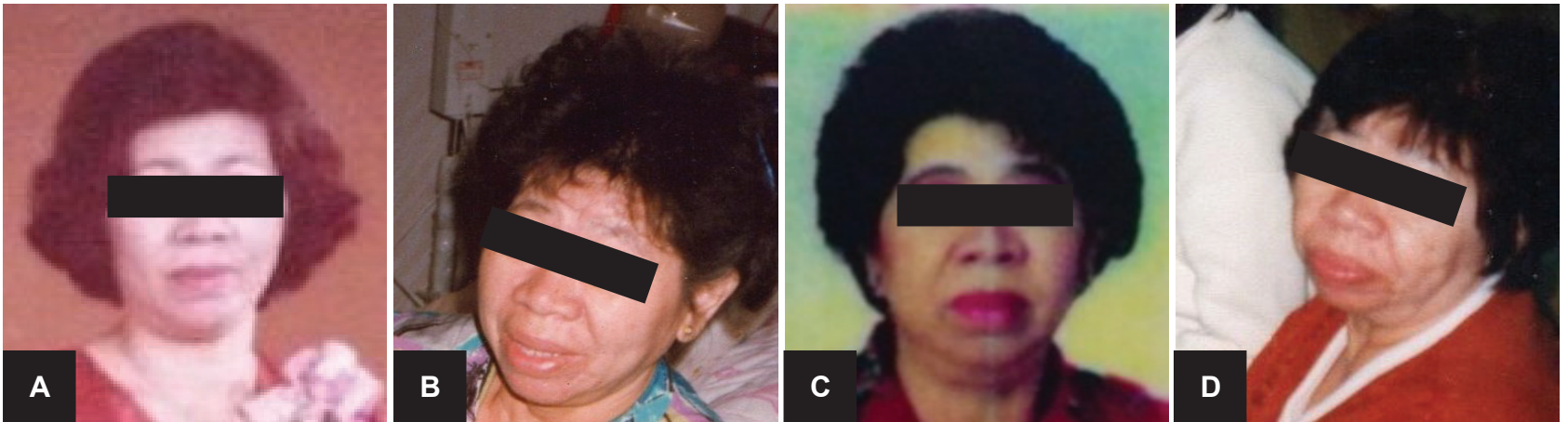

Figure 1. Pictures of the patient throughout the years (A) 1980s (B) 1989 (C) 2000 (D) 2001.
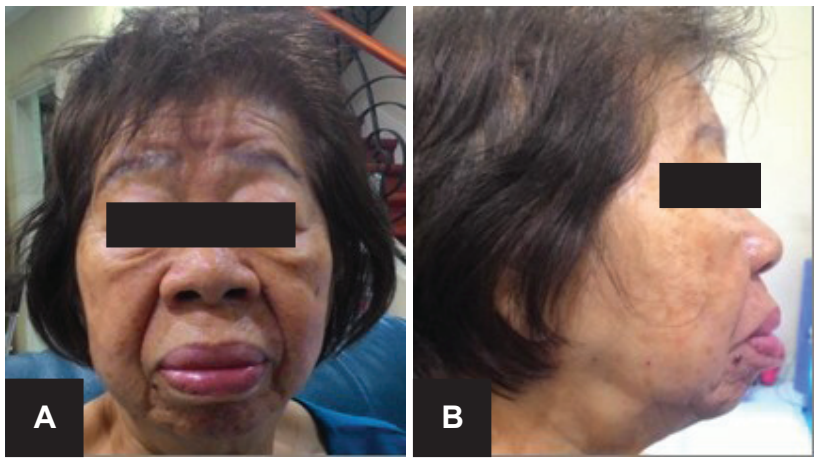

Figure 2. Latest front $(A)$ and lateral $(B)$ pictures of the patient taken July 2015.

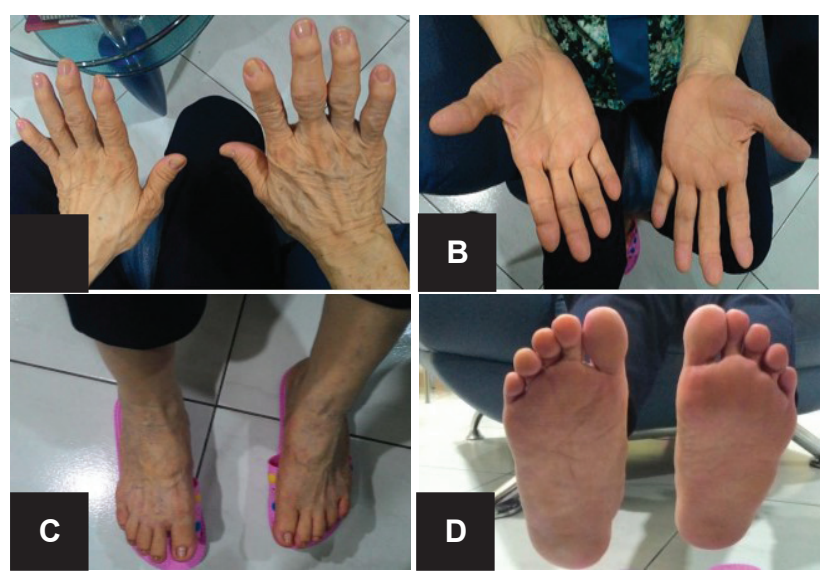

Figure 3. Picture of the patient's hands - dorsal $(A)$ and palms (B); patient's feet - dorsal (C) and soles (D). Incidentally note that both her right hand and foot is larger than the left.

to her Sandostatin regimen. But unfortunately, due to cost, difficulty in procuring the medication, and the bothersome nature of administration (subcutaneous), patient stopped Sandostatin-LAR and continued with cabergoline, $0.5 \mathrm{mg}$, 2 tablets twice a week. A repeat pituitary MRI 2 years later (2002) showed an "empty sella." Another MRI scan of the pituitary was done in 2004, where no pituitary adenoma was again identified (Appendix A).
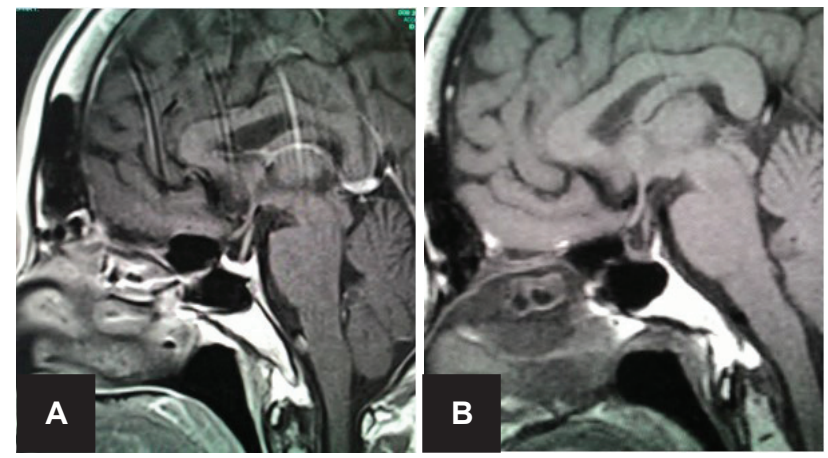

Figure 4. $T 1$ weighted sagittal MRI image of the pituitary post contrast (A) 2015 and (B) 2004. Both showing a small pituitary gland which is pressed against the sellar floor with no internal hypoenhancement post-contrast.

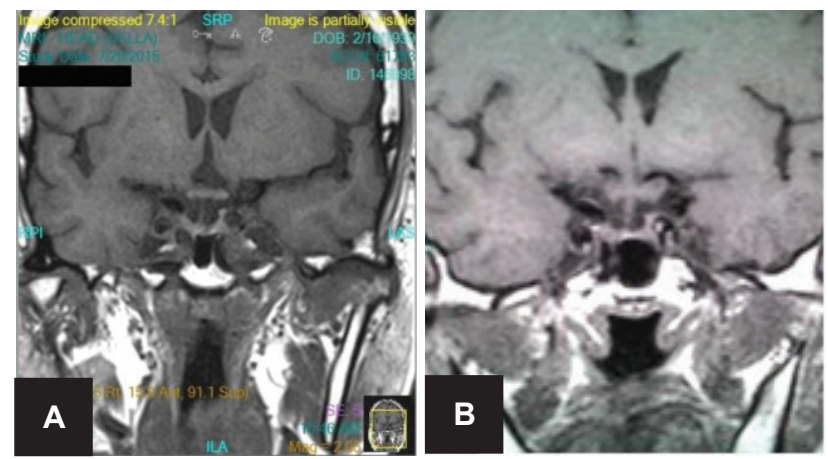

Figure 5. T1 weighted coronal MRI image of the pituitary post contrast (A) 2015 and (B) 2004. Both showing a small pituitary gland which is pressed against the sellar floor with no internal hypoenhancement post-contrast.

In June 2015, patient consulted in our institution for diabetes management follow up. The attending endocrinologist still noted coarse facial features, enlarged hands and feet (Figure 1-3). She was noted to be hypertensive on blood pressure lowering medications and diabetic on oral hypoglycemic agents. Repeat IGF-1 and levels of IGF-1 through the years are shown on Table 2. A repeat MRI imaging of the sella revealed normal pituitary, with no evidence of pituitary adenoma (Figure 4-5). 


\begin{tabular}{|c|c|c|c|}
\hline & 2015 & 2016 & 2017 \\
\hline IGF-1 & $52(90-220)$ & $180(59-177)$ & $181(59-177)$ \\
\hline Prolactin & $0.65(5.18-26.53)$ & - & - \\
\hline Growth Hormone & $1.44(0.01-3.61)$ & $0.37(0.01-3.61)$ & $0.18(0.01-3.61)$ \\
\hline
\end{tabular}

IGF-1 Level (ng/ml) from 2000-2017

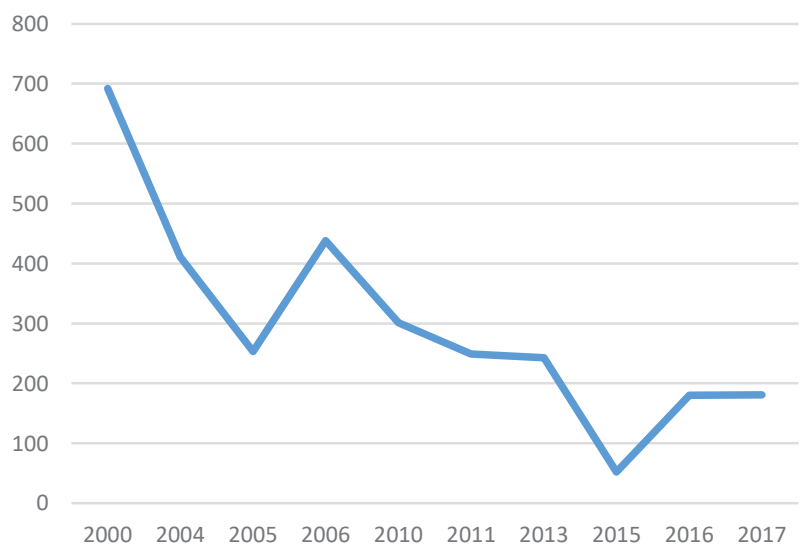

Figure 6. Line graph of IGF-1 level in ng/ml from 20002017.

\section{DISCUSSION}

A hyperfunctioning growth hormone-secreting pituitary adenoma is the most common cause of acromegaly. Rarer causes are ectopic or hypothalamic growth hormone releasing hormone-secreting tumor. Since the signs and symptoms of acromegaly are indolent, the time from onset of signs and symptoms to diagnosis of acromegaly is long, usually taking years. The pituitary adenomas that cause growth hormone excess are usually large and are easily identified on routine MRI imaging of the sella. Treatment would then involve resection of the pituitary adenoma via transsphenoidal surgery.

In rare cases, a pituitary MRI may show negative results. A contrast enhanced CT scan of the chest and abdomen is the next step to detect ectopic sources of $\mathrm{GH}$ or $\mathrm{GH}$ releasing hormone (GHRH) production. Acromegaly without imaging evidence of a pituitary macroadenoma or an ectopic source is very rare. Lonser et al., reported 6 patients (mean age 56 years) with signs, symptoms and biochemical evidence of acromegaly without pituitary adenoma on imaging and an ectopic source. ${ }^{1}$ All underwent surgical exploration of the pituitary gland and GH-secreting pituitary adenoma ranging from 5 to 6.7 $\mathrm{mm}$ were identified and resected. Khandelwal et al., reported one patient with acromegaly who also underwent surgical exploration of the pituitary, were a GH-secreting pituitary adenoma was identified and resected. ${ }^{2}$

We present our 76-year-old patient with acromegaly without pituitary evidence of a pituitary adenoma and without evidence of an ectopic source who underwent medical therapy using cabergoline $0.5 \mathrm{mg}$, 2 tablets twice a week for 14 years. Patient reports less choking and snoring symptoms and slight decrease in size of her tongue and improved sleep. Due to her age, she is not a good candidate for surgical exploration of the pituitary nor did she consent to the procedure. Other treatment options include somatostatin analogues (octreotide and lanreotide), dopamine agonists (bromocriptine and cabergoline), pegvisomant, and radiotherapy; these treatment modalities are reserved for persistent disease after surgery, for unresectable tumors or poor surgical candidates. Target goal of therapy is to reach an agenormalized serum IGF-1 value, and a random growth hormone $(\mathrm{GH})<1.0 \mu \mathrm{g} / \mathrm{L}$. A target $\mathrm{GH}<1 \mu \mathrm{g} / \mathrm{L}$ and normalized IGF-1 values have each been shown to correlate with mortality risk reduction. ${ }^{3}$

Octreotide long acting release (LAR), and deep subcutaneous lantreotide depot/autogel are administered monthly. Octreotide LAR dose is $20 \mathrm{mg}$ monthly with dose titration every 3-6 months down to $10 \mathrm{mg}$ or up to 40 mg monthly. Lanreotide autogel/depot starting dose is 90 $\mathrm{mg}$ monthly, with dose titrations down to $60 \mathrm{mg}$ or up to $120 \mathrm{mg}$ monthly. Serum IGF-1 and GH is measured 12 weeks just prior to the next dose. Octreotide LAR produces normalization of IGF-1 levels in only 34\% of patients, but with clinical relevant reduction of $\mathrm{GH}$ in $72 \%$ of patients, and a significant tumor reduction in $75 \%$ of patients. ${ }^{4}$ Lantreotide autogel, also achieves biochemical control in $34 \%$ of patients, ${ }^{5}$ with tumor shrinkage achieved in $62.9 \%$ of patients. $^{6}$ A recently concluded phase 3 controlled trial of pasireotide, a new multireceptor targeted somatostatin analogue, reported better biochemical control and tumor size reduction in patients initially poorly responsive to first generation somatostatin analogue. ${ }^{7}$

Pegvisomant, a human GH receptor antagonist, competes with GH for binding at its receptor and block production of IGF-1. Pegvisomant is administered as 10, 15, or $20 \mathrm{mg}$ daily injections. Serum GH levels should not be measured because GH hypersecretion persists in patients given Pegvisomant; instead, IGF-1 level is recommended as the only useful biomarker to monitor treatment efficacy. Pegvisomant reduces IGF-1 levels in $81-97 \%$ of patients, ${ }^{8-10}$ with 5 year efficacy of $63.2 \%$ with a mean dose of $18 \mathrm{mg}$ daily. ${ }^{11}$

Dopamine agonists (bromocriptine and cabergoline) are of limited efficacy in the treatment of acromegaly, with high doses required to achieve control. Discontinuation of treatment may result in rebound growth hormone hypersecretion. Bromocriptine is usually required at a 
dose of 20-30 mg per day; while cabergoline may require high doses of up to $1 \mathrm{mg}$ per day to achieve control. ${ }^{12} \mathrm{~A}$ metaanalysis showed cabergoline to be approximately $34 \%$ effective in attaining biochemical control,13 with response appearing to decrease with time. In the study by Freda et al., in 2004, only $21 \%$ of subjects were controlled after 18 months of cabergoline administration. ${ }^{14}$

Sandostatin LAR administration via subcutaneous route was initially given, however, no improvement in IGF-1 levels were seen; hence, cabergoline was added to her regimen. Octreotide was eventually withdrawn due to the bothersome nature of administration and costs. She was then switched to cabergoline regimen only. Although we found no studies on the efficacy of carbergoline in the long run, the latest results of IGF-1 of our patient may indicate efficacy of cabergoline in patients with continued intake (Table 3), although further monitoring is still needed. A repeat whole abdominal CT scan done in March 2017 was still negative for an ectopic GH-producing tumor. A repeat chest and neck CT scan is still pending.

\section{CONCLUSION}

A trial of dopamine agonist, cabergoline, may be given to patients with acromegaly and no imaging evidence of a pituitary adenoma or an ectopic source, who are poor surgical candidates and unresponsive to octreotide or other somatostatin analogues, with consideration of cost, may be given a trial of dopamine agonist, specifically cabergoline. Carbegoline therapy may have sustained response in supressing GH and IGF-1 with time, as seen in our patient who has taken cabergoline for 17 years.

\section{Ethical Consideration}

Patient consent was obtained before submission of the manuscript.

\section{Statement of Authorship}

All authors certified fulfillment of ICMJE authorship criteria.

\section{Author Disclosure}

The authors declared no conflict of interest.

\section{Funding Source}

None.

\section{References}

1. Lonser R, Kindzelski BA, Mehta GU, Jane JA Jr., Oldfield EH. Acromegaly without imaging evidence of pituitary adenoma. J Clin Endocrinol Metab. 2010;95(9):4192-6. PMCID: PMC2936064. https:// doi.org/10.1210/jc.2010-0570.

2. Khandelwal D, Khadgawat R, Mukund A, Suri A. Acromegaly with no pituitary adenoma and no evidence of ectopic source. Indian J Endocrinol Metab. 2011;15(Suppl 3):S250-2. PMCID: PMC3183531. https://doi.org/10.4103/2230-8210.84878.

3. Katznelson L, Laws E, Melmed S, et al. Acromegaly: An endocrine society clinical practice guideline. J Clin Endocrinol Metab. 2014 99(11):3933-51. PMID: 25356808. https://doi.org/10.1210/jc.2014-2700.

4. Mercado M, Borges F, Bouterfa H, et al. A prospective, multicenter study to investigate the efficacy, safety and tolerability of octreotide LAR (long-acting repeatable octreotide) in the primary therapy of patients with acromegaly. Clin Endocrinol (Oxf). 2007;66(6):859-68. PMID: 17465997. PMCID: PMC1974838. https://doi.org/10.1111/ j.1365-2265.2007.02825.x.

5. Caron PJ, Bevan JS, Petersenn, et al. Tumor shrinkage with lanreotide Autogel $120 \mathrm{mg}$ as primary therapy in acromegaly: Results of a prospective multicenter clinical trial. J Clin Endocrinol Metab. 2014;99(4):1282-90. PMID: 24423301. PMCID: PMC4009579. https:// doi.org/10.1210/jc.2013-3318.

6. Caron P, Bevan J, Petersen S, et al. Effects of lanreotide Autogel primary therapy on symptoms and quality-of-life in acromegaly: Data from the PRIMARYS study. Pituitary. 2016;19(2):149-57. PMID: 26603536. PMCID: PMC4799252. https://doi.org/10.1007/s11102-015-0693-y.

7. Bronstein M, Fleseriu M, Neggers S, et al. Switching patients with acromegaly from octreotide to pasireotide improves biochemical control: Crossover extension to a randomized, double-blind, Phase III study. BMC Endocr Disord. 2016;16:16. PMID: 27039081. PMCID: PMC4818908. https://doi.org/10.1186/s12902-016-0096-8.

8. Trainer PJ, Drake WM, Katznelson L, et al. Treatment of acromegaly with the growth hormone-receptor antagonist pegvisomant. N Engl J Med. 2000;342(16):1171-7. PMID: 10770982. https://doi.org/10.1056/ NEJM200004203421604.

9. van der Lely AJ, Hutson RK, Trainer PJ, et al. Long-term treatment of acromegaly with pegvisomant, a growth hormone receptor antagonist. Lancet. 2001;358(9295):1754-9. PMID: 11734231.

10. Shimatsu A, Nagashima M, Hashigaki S, Ohki N, Chihara K. Efficacy and safety of monotherapy by pegvisomant, a growth hormone receptor antagonist, in Japanese patients with acromegaly. Endocr J.2016;63(4):337-47. PMID: 26796763. https://doi.org/10.1507/ endocrj.EJ15-0619.

11. van der Lely AJ, Biller BM, Brue $\mathrm{T}$, et al. Long-term safety of pegvisomant in patients with acromegaly: Comprehensive review of 1288 subjects in ACROSTUDY. J Clin Endocrinol Metab. 2012;97(5): 1589-97. PMID: 22362824. https://doi.org/10.1210/jc.2011-2508.

12. Carroll P, Jenkins P. Acromegaly. In: De Groot L Chrousos, Dungan $\mathrm{K}$, et al, ed, 2016. Retrieved from http://www.endotext.org/chapter/ acromegaly/. Bookshelf ID: NBK278943. PMID: 25905160.

13. Sandret L, Maison P, Chanson P. Place of cabergoline in acromegaly: A meta-analysis. J Clin Endocrinol Metab. 2011;96(5):1327-35. PMID: 21325455. https://doi.org/10.1210/jc.2010-2443.

14. Freda PU, Reyes CM, Nuruzzaman AT, Sundeen RE, Khandji AG, Post KD. Cabergoline therapy of growth hormone and growth hormone/prolactin secreting pituitary tumors. Pituitary. 2004;7(1):2130. PMID: 15638294.

\footnotetext{
Authors are required to accomplish, sign and submit scanned copies of the JAFES Author Form consisting of: (1) Authorship Certification, that all the requirements for authorship have been met by each author, and that the final version of the manuscript has been read and approved by all authors; (2) the Author Declaration, that the article represents original material that is not being considered for publication or has not been published or accepted for publication elsewhere; (3) the Statement of Copyright Transfer laccepted manuscripts become the permanent property of the JAFES and are licensed with an Attribution-Share Alike-Non-Commercial Creative Commons License. Articles may be shared and adapted for non-commercial purposes as long as they are properly cited]; and the ICMJE form for Disclosure of Potential Conflicts of Interest. For original articles, authors are required to submit a scanned copy of the Ethics Review Approval of their research as well as registration in trial registries as appropriate. For manuscripts reporting data from studies involving animals, authors are required to submit a scanned copy of the Institutional Animal Care and Use Committee approval. For Case Reports or Series, and Images in Endocrinology, consent forms, are required for the publication of information about patients; otherwise, authors declared that all means have been exhausted for securing such consent. Articles and any other material published in the JAFES represent the work of the author(s) and should not be construed to reflect the opinions of the Editors or the Publisher.
} 


\section{APPENDIX A}

MRI scan of the pituitary showing pre- and post-contrast phase (top, 2015 scan; bottom, 2004 scan).
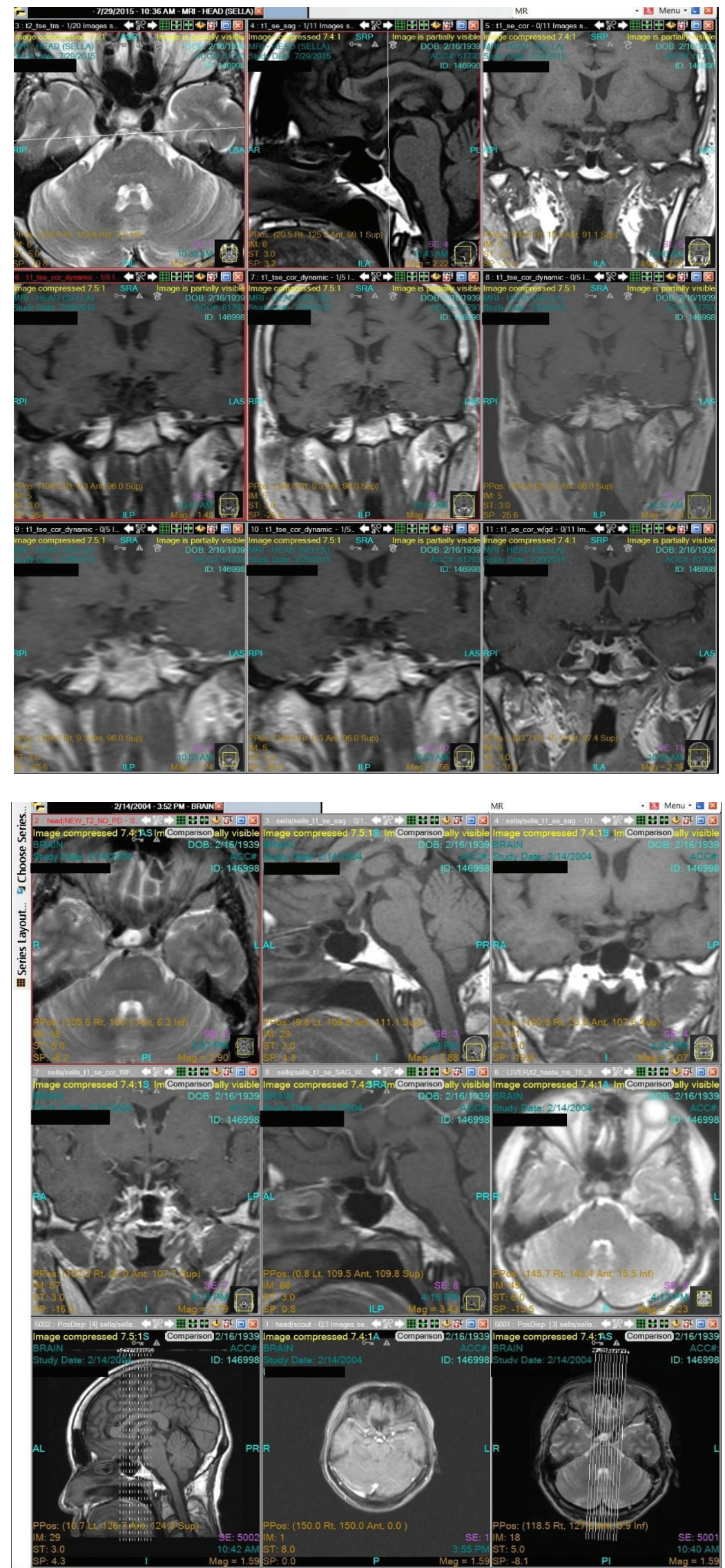